\title{
CONTRIBUIÇÕES PARA A GESTÃO DE REDES INTERORGANIZACIONAIS: FATORES DETERMINANTES PARA A SAIIDA DE EMPRESAS PARCEIRAS
}

\author{
Leander Luiz Klein \\ kleander88@gmail.com \\ Universidade Federal de Santa Maria - Santa Maria, RS / Brasil \\ Breno Augusto Diniz Pereira \\ brenodpereira@gmail.com \\ Universidade Federal de Santa Maria - Santa Maria, RS / Brasil
}

http://dx.doi.org/10.1590/1413-2311068201239395

Recebido em 07/11/2012

Aprovado em 19/11/2013

Disponibilizado em 01/08/2014

Avaliado pelo sistema double blind review

Revista Eletrônica de Administração

Editor: Luís Felipe Nascimento

ISSN 1413-2311 (versão on-line)

Editada pela Escola de Administração da Universidade Federal do Rio Grande do Sul.

Periodicidade: Quadrimestral

Sistema requerido: Adobe Acrobat Reader.

\section{RESUMO}

As redes de cooperação entre empresas são estratégias usadas pelos gestores para atuar no mercado com o intuito de gerar mais valor às empresas e obter vantagem competitiva. Entretanto, verifica-se empiricamente que um número significativo de empresas saem das redes em que estavam inseridas. Nesse sentido, este estudo tem como objetivo identificar os fatores determinantes da saída de empresas das redes interorganizacionais das quais participavam. Para isso, foi realizado um estudo quantitativo com 140 empresas que pertenciam a redes de cooperação do estado do Rio Grande do Sul, Brasil. Para a coleta de dados, foi utilizado um questionário formado por 15 dimensões distintas, cada uma composta por 5 questões. Os dados foram tabulados em uma planilha do Excel e, posteriormente, analisados com a utilização do sofware AMOS 18. Os resultados confirmaram como fatores determinantes da saída das empresas das redes os Laços Sociais Anteriores Fracos, Seleção de Parceiros não estruturada, Gestão Individualizada, Falta de Confiança e Comprometimento, Baixa de Aprendizagem Interorganizacional, dentre outros. Os fatores determinantes encontrados nessa pesquisa ressaltaram a dificuldade que impera sobre as estruturas de governança e a gestão de redes. O desafio é organizar a rede de forma a evitar possíveis disfunções oriundas das decisões da gestão e amenizar os problemas identificados, fazendo com que as empresas se mantenham nas redes, gerando retornos e vantagens competitivas a elas.

Palavras- Chave: Redes Interorganizacionais; Determinantes para saída de Empresas; Gestão de Redes; Problemas nas Redes.

REAd | Porto Alegre - Edição 78 - N 2 - maio/agosto 2014 - p. 305-340 
Contribuições para a gestão de redes interorganizacionais: fatores determinantes para a saída de empresas parceiras

\title{
CONTRIBUTIONS TO THE INTERORGANIZATIONAL NETWORK MANAGEMENT: DETERMINANT FACTORS TO LEAD PARTNER COMPANIES TO EXIT
}

\begin{abstract}
The cooperation networks among organizations are strategies used by the managers to act in the Market to gather more value to companies and obtain competitive advantage. However, empirically is possible to verify that there is a significant number of companies leaving the networks in which they were inserted. Thus, this study aims to identify the determinant factors which lead to companies leaving the interorganizational networks they used to take part in. Therefore, a quantitative study was conducted with 140 companies belonging to cooperation networks in the state of Rio Grande do Sul, Brazil. To data collection a questionnaire was used, it was structured in 15 different dimensions, each one composed of 5 questions. The data was tabulated in na Excel spreadsheet and then analyzed through the software AMOS 18. The results have confirmed as determinant factors to companies exit the networks the Previous Weak Social Ties, Bad Partners Selection, Individualized Management, Lack of Confidence and Commitment, Low Interorganizational Learning, among others. The determinant factors evaluated in this research emphasize the difficulty found about the governance structures and management in networks. The challenge is to organize the network in a way to avoid possible disorders coming from the managing decisions and reduce the problems identified in this study, in order to maintain the companies in the network, creating return and competitive advantages to those.
\end{abstract}

Keywords: Interorganizational Networks; Factors to Companies Exit; Networks Management; Networks Problems.

\section{CONTRIBUCIONES PARA LA GESTIÓN DE REDES \\ INTERORGANIZACIONALES: FACTORES DETERMINANTES PARA LA SALIDA DE EMPRESAS PARCEIRAS}

\begin{abstract}
RESUMEN
Las redes de cooperación entre empresas son estrategias utilizadas por los gerentes para operar en el mercado con el fin de generar más valor a sus negocios y obtener ventaja competitiva. Sin embargo, se encontró empíricamente que un número significativo de empresas salian de la red en la que se insertan. Así, este estudio tiene como objetivo identificar los determinantes de la salida de empresas de las redes interorganizacionales que participaron. Para esto, un estudio cuantitativo con 140 empresas pertenecientes a redes de cooperación del estado de Rio Grande do Sul, in Brasil, se llevó a cabo. Para recopilar los datos, se utilizó un cuestionario compuesto por 15 dimensiones distintas, cada una compuesta por 5 preguntas. Los datos se tabularon en una hoja de cálculo de Excel y luego analizados utilizando el sofware AMOS 18. Los resultados confirmaron como factores determinantes de la salida de las empresas de las redes los Débiles Vínculos Sociales Anteriores, la Selección REAd | Porto Alegre - Edição 78 - N 2 - maio/agosto 2014 - p. 305-340
\end{abstract}




\section{Leander Luiz Klein \& Breno Augusto Diniz Pereira}

de Socios no Estructurada, la Administración Individualizada, la Falta de Confianza y Compromiso, Baja Aprendizaje Interorganizacional, entre otros. Los factores determinantes que se encuentran en este estudio destacaron la dificultad que prevalece en las estructuras de gobierno y gestión de redes. El desafío es organizar la red con el fin de evitar posibles fallos de funcionamiento derivados de las decisiones de gestión y mitigar los problemas identificados, haciendo que las empresas si mantenam en las redes, con la generación de rendimientos y ventajas competitivas a ellas.

Palabras Clave: Redes interorganizacionales; Determinantes de la salida de Empresas; Gestión de Red; Los problemas en las redes.

\section{INTRODUÇÃO}

As parcerias interorganizacionais, apesar de não serem recentes, são referidas, em grande parte da literatura sobre o assunto, como uma forma adequada para as organizações manterem-se competitivas e como alternativa de crescimento. A importância delas é bastante visível no que diz respeito às empresas de pequeno e médio porte que têm, geralmente, mais dificuldades de agirem isoladamente. O formato organizacional de empresas em redes está relacionado à complementaridade de competências, informações diversificadas e direcionadas, aprendizado e inovação (LIN; YANG; ARYA, 2009), que pode diminuir a incerteza quanto às atividades, suprir as necessidades de recursos das empresas parceiras em redes e ser "uma importante fonte de geração de valor" (CORSTEN; GRUEN; PEYINGAUS, 2011, p. 550).

Entretanto, atualmente, a estrutura e a gestão das redes levantam novas questões. Chao (2011), por exemplo, explica que a cooperação de empresas em redes pode ser vista como uma série de processos de tomada de decisões envolvendo a interação entre as firmas, isso porque a insuficiente compreensão ou a falta de comprometimento de uma das partes pode levar a uma variedade de erros e vieses, e afetar a estabilidade do processo cooperativo, e em alguns casos a continuidade da rede. Aparentemente, se uma empresa sai de uma rede houve um problema na relação entre as empresas, pois este tipo de empreendimento não é formatado para que elas saiam, a não ser que a rede tenha um prazo determinado de existência, o que não é o foco deste estudo.

Tem-se verificado, empiricamente, que as redes somente trazem vantagens às empresas parceiras se várias condições, muitas vezes interdependentes, forem preenchidas, o que torna o processo de gestão/governança ainda mais complexo. Muitas redes não 
Contribuições para a gestão de redes interorganizacionais: fatores determinantes para a saída de empresas parceiras

conseguem consolidar suas estruturas e seus modelos de gestão, pois aspectos e fatores negativos podem surgir nas relações, a ponto de os investimentos efetuados não serem compensados, fazendo com que elas saiam das redes e acabem por terem insucesso. Estudos como o de Sheng-Yue e Xu (2005) ressaltam que a taxa de falência de redes é superior a 50\%. Diante disso, questiona-se: as redes realmente proporcionam benefícios e competitividade? Por que algumas empresas se desvinculam delas? Quais as razões que levam a esta retirada? Por que as empresas saem? A resposta a essas perguntas é justamente o objeto que motiva este estudo.

Para Pesämaa (2007), muitas empresas não estimam as desvantagens/custos de se inserirem em redes e não são capazes de avaliar se estão aptas a entrar nas redes, ou se tal estratégia é um bom negócio. A saída de uma empresa integrante da rede pode ser compensada, em termos de sua competitividade, com a entrada de outra empresa, mas esta 'rotatividade' de empresas na rede gera dificuldades para o fortalecimento do grupo, levando a diminuição da otimização dos ganhos e do valor gerado às empresas parceiras. A identificação dos principais problemas e determinantes levam a saída de empresas das redes auxilia os gestores, tanto das empresas quanto das redes, na gestão desses empreendimentos conjuntos. Diante disso, este trabalho tem o objetivo de identificar os fatores os determinantes da saída de empresas das redes de cooperação em que estavam inseridas.

O estudo se justifica pelo fato de existir pouco conhecimento a respeito do tema e por ser limitado o conhecimento sobre quais esforços e aspectos, bem como quando e como eles são susceptíveis de conduzir ao bom desempenho de alianças colaborativas CHEN (2010). Para Sadowski e Duysters (2008) pouco se sabe a respeito de falha ou insucesso de arranjos estratégicos. Assim, uma maior compreensão sobre o assunto, verificando os problemas que levam à saída de empresas parceiras de redes, pode ajudar a amenizar problemas e dificuldades que surgem desde o processo de formação até o fortalecimento de redes, contribuindo para a sua gestão. Além disso, este estudo se justifica por diminuir as lacunas existentes no entendimento desse assunto e visa, consequentemente, corroborar com a consolidação de um corpo teórico sobre o fenômeno.

REAd | Porto Alegre - Edição 78 - N 2 - maio/agosto 2014 - p. 305-340 


\section{ANTECEDENTES, PROCESSOS E RESULTADOS PERCEBIDOS DA COLABORAÇÃO}

Para compreender e esquematizar os principais determinantes e possíveis fatores que levam as empresas a saírem de redes interorganizacionais, este trabalho foi constituído por pesquisa prévia englobando teorias e estudos sobre falência e problemas de redes interorganizacionais e integrando os fatores influenciadores para saída de empresas no framework ilustrado na Figura 1.

A proposição deste framework de referência é feita ampliando o modelo de Chen (2010) que propôs a integração de antecedentes, processos e resultados percebidos da colaboração. A diferença é que no estudo de Chen (2010), o autor identificou os determinantes para efetividade da colaboração das empresas em redes, e nesta pesquisa visam-se os determinantes para saída delas da rede. Cada um dos determinantes identificados é descrito e explicado nos tópicos seguintes deste artigo.

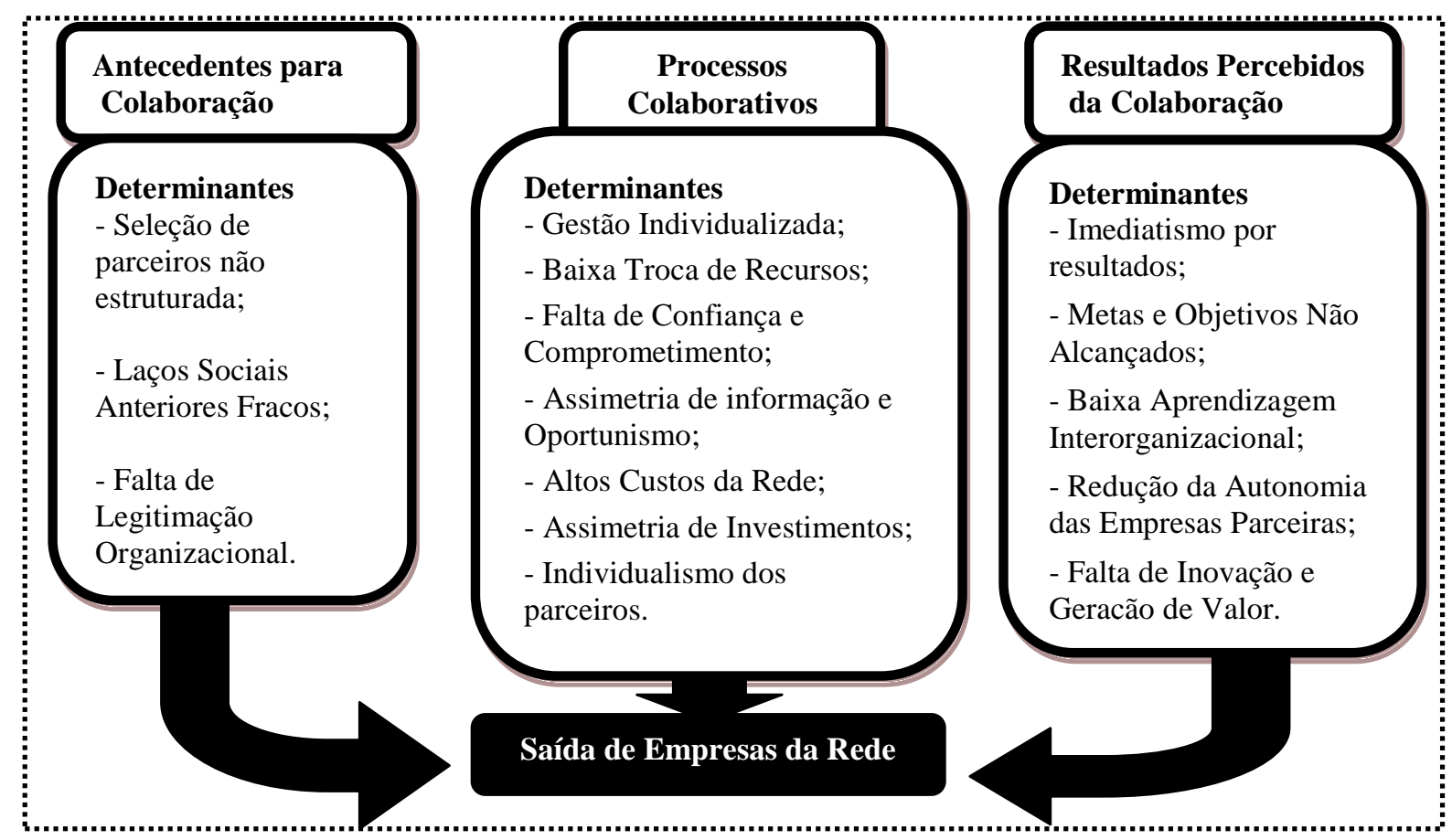

Figura 1 - Framework dos determinantes da saída de empresas de redes

Fonte: elaborado pelos autores

\subsection{Antecedentes para colaboração}

\subsubsection{Seleção de Parceiros Não Estruturada}

REAd | Porto Alegre - Edição 78 - Nº 2 - maio/agosto 2014 - p. 305-340 
Contribuições para a gestão de redes interorganizacionais: fatores determinantes para a saída de empresas parceiras

A decisão do gestor de uma empresa em firmar parceria com uma organização particular ou não, pode ser influenciada pela dificuldade de encontrar parceiros, denominada como "imperfeição do lado da oferta" por Van Slyke (2007). As diferentes orientações estratégicas de cada sócio podem ser um problema para gestão da rede, que terá que lidar com as perspectivas diferentes de cada empresa parceira. Graddy e Chen (2006) observaram que, mesmo se as organizações estavam dispostas a cumprir com as exigências de financiamento exigidas para formar uma rede, elas foram limitadas pela sua capacidade em potencial. Hitt $e t$ al. (2000) e Tsang (2002) sugerem que a seleção de parceiros é um fator determinante de sucesso da aliança, devido a necessidade de alinhamento de recursos específicos e a possibilidade de troca entre os integrantes.

Considerando a teoria dos custos de transação, a seleção de empresas com recursos congruentes ou adequadas aos propósitos de formação da rede reduz o tempo e os custos com a elaboração e negociação dos contratos e o esforço necessário para a coordenação das atividades e adaptação dos termos contratuais às novas circunstâncias (WILLIAMSON, 1985). Certos tipos de características dos sócios promovem a confiança entre os integrantes da relação e tornam a colaboração mais fácil (CHILE e McMACKIN, 1996; OSTROM, 1990). 'Uma compreensão de modelos da seleção do sócio e sua 'compatibilidade' podem realçar o desempenho da rede e desse modo aumentar a vantagem competitiva de uma firma em mercados" (HITT et al., 2000, p. 13). Para Douma et al. (2001), a dificuldade é ajustar as estratégias às empresas, relacionando aspectos como o equilíbrio complementar de informações, benefícios recíprocos e a harmonia entre as empresas integrantes. Estes aspectos levam a seguinte hipótese de pesquisa:

H1: A seleção de parceiros não estruturada está positivamente relacionada à saída de empresas parceiras.

\subsubsection{Laços Sociais Anteriores Fracos}

Gulati (1995) argumenta que a capacidade de uma organização para aderir a uma aliança é limitada pela sua rede social. O complexo de relações entre membros de um sistema social de diferentes dimensões, recursos e habilidades designa a possibilidade de formar uma relação e, nesse sentido, os laços sociais anteriores a formação da rede podem aumentar a possibilidade de sucesso desta. Para Chen (2010), uma organização que tem limitações de 
Leander Luiz Klein \& Breno Augusto Diniz Pereira

capacidade na comunidade (inadimplência com fornecedores) e falta de uma rede social (contatos anteriores) terá uma parceria resultante improvável de ser associada com resultados positivos. Em suma, o comportamento econômico dos agentes é constrangido por estruturas sociais que são construídas ao longo do tempo (GRANOVETTER, 1985) e que podem delinear a permanência ou saída da organização do arranjo cooperativo, a rede. Diante disso, propõem-se a seguinte hipótese de pesquisa:

H2: Ter uma relação ou laços sociais anteriores fracos estabelece uma relação positiva com a saída de empresas da rede.

\subsubsection{Falta de Legitimação Organizacional}

Em seus estudos, Chen (2010) coloca que as parcerias entre empresas são estimuladas por motivações organizacionais, como a geração de legitimidade às demais empresas parceiras e aos stakeholders. Uma maneira de isto acontecer seria quando a colaboração é susceptível de melhorar a reputação da organização. Parcerias, alianças ou redes de empresas são vistas como desejáveis e, frequentemente, são encorajadas e solicitadas pelos donos e financiadores de empresas tendo em vista o aumento da legitimidade das empresas (PROVAN; KENIS; HUMAN, 2008; BRYSON; CROSBY; STONE, 2006).

A legitimidade resume as atividades reconhecidas das empresas pelos seus principais stakeholders (LAWRENCE; WICKINS; PHILLIPS, 1997). Pesämaa (2007) explica que essas atividades referem-se às exigências legais, os recursos que tornam seus serviços e/ou produtos atraentes e, finalmente, a estrutura que cerca a empresa e que faz potenciais interessados se sentirem seguros e confiantes na realização de trocas com a empresa. As principais partes interessadas em geral esperam que uma empresa possa provar apoios políticos, recursos essenciais e estabilidade financeira. Assim, a falta de legitimidade organizacional promovida às empresas integrantes da rede é um determinante para saída de empresas das redes. Diante disso, tem-se a seguinte hipótese de pesquisa:

H3: A falta de legitimidade gerada às empresas inseridas na rede está positivamente relacionada à saída de empresas parceiras.

\subsection{Processos colaborativos}

\subsubsection{Gestão Individualizada}

REAd | Porto Alegre - Edição 78 - N² 2 - maio/agosto 2014 - p. 305-340 
Contribuições para a gestão de redes interorganizacionais: fatores determinantes para a saída de empresas parceiras

O que diferencia a gestão de redes de empresas da governança corporativa é que naquela os atores são as empresas, e não os indivíduos, como nesta. Em uma rede cooperativa, a gestão é o resultado de um processo de negociação entre os respectivos dirigentes das empresas participantes no acordo (WEGNER e PADULA, 2010). Estas empresas concordam em perder sua liberdade, até certo ponto, e permitem que a gestão da cooperação coordene alguns aspectos de seus negócios, sob o sistema de regras criadas pelo grupo (ALBERS, 2005).

A dificuldade inerente a esse processo se deve ao fato de que a cooperação demanda grandes esforços de coordenação para o alinhamento de objetivos e propósitos, gerando complexidade gerencial e incerteza (PARK e UNGSON, 2001). Nesse contexto, a tomada de decisão conjunta, que se refere ao envolvimento conjunto dos parceiros no planejamento dos serviços e definição de metas, é característica inerente ao bom andamento das atividades desenvolvidas na rede. Anderson, Lodish e Weitz (1987) e Dwyer, Schurr, Oh (1987) sugeriram que a tomada de decisões e o envolvimento de todos na formulação dos objetivos são aspectos fundamentais da colaboração e que faz parcerias de sucesso. Contrariamente, uma gestão individualizada e centrada nas decisões de alguns integrantes da rede que gerem a rede priorizando suas necessidades, tende a tornar manifesta a existência de conflitos e desajustes quanto às decisões tomadas. $\mathrm{O}$ argumento é testado com a seguinte hipótese de pesquisa:

H4: A gestão individualizada tem relação positiva com a saída de empresas parceiras da rede.

\subsubsection{Baixa Troca de Recursos}

A teoria baseada em recursos sugere que as organizações entrarão em parcerias /alianças, quando um dos parceiros pode contribuir com recursos ou capacidades, que não são possuídas por outra organização (PFEFFER; SALANCIK, 1978 e DYER;SINGH, 1998). Por meio do estabelecimento de alianças estratégicas com outras empresas, uma organização pode ganhar acesso ao conhecimento tácito, habilidades complementares, novas tecnologias ou mercados e a possibilidade de fornecer uma maior gama de produtos e serviços de outra maneira. A colaboração, provavelmente, será vista como eficaz se os parceiros estão comprometidos com a troca de recursos um com os outros para benefício mútuo. O processo 
Leander Luiz Klein \& Breno Augusto Diniz Pereira

de intercâmbio de recursos é caracterizado pela estreita interdependência percebida entre os parceiros e pelos benefícios de trabalhar em conjunto, em comparação com o 'trabalhar sozinho' (CHEN, 2010).

No estudo feito por Chen (2010), foram identificados recursos a serem adquiridos dos parceiros para relação. Alguns recursos são escassos como, por exemplo, a capacidade de oferta, a experiência em serviços específicos e a cobertura geográfica, e outros são regionais e intangíveis como os conhecimentos locais, o acesso a novos mercados e à competência cultural e linguística. Acrescenta-se aqui, a visão de Hastings (1996) sobre a sinergia de recursos. Ele coloca que as empresas inseridas nas redes devem acrescentar valor, combinando recursos provenientes das diferenças inerentes entre seus parceiros, para possibilitar a estabilidade e reduzir as incertezas. Com base, nisso tem-se a seguinte hipótese de pesquisa:

H5: A baixa troca de recursos entre as empresas parceiras está é um motivo para a desistência de integrantes da rede do processo colaborativo.

\subsubsection{Falta de Confiança e Comprometimento}

No entendimento de Parast e Digman (2008), a confiança entre os parceiros é, certamente, um dos fatores mais citados na literatura, sendo considerada como requisito para a cooperação. Como mencionam Verschoore e Balestrin (2008), a confiança é um fator das relações sociais que se estabelecem a partir da criação das redes de cooperação, pois elas aproximam os agentes e, dessa forma, as relações acabam extrapolando o plano econômico. Para Fryxell; Dooley e Vryza (2002) o nível de confiança entre os parceiros é também uma condição fundamental para o sucesso da aliança.

Lourenzani, Silva e Azevedo (2006) indicam a confiança como fator indispensável entre os relacionamentos interorganizacionais e a consideram como uma condição para que se estabeleça compromisso entre os atores envolvidos. A confiança e o comprometimento criam um contexto de colaboração social propício à partilha de informação e aprendizagem (DYER e CHU 2003) . Do contrário, sem a presença desses dois aspectos em um ambiente de rede, muitas trocas e atividades conjuntas são dificultadas ou não efetivadas, e as empresas passam a sair dos arranjos cooperativos nos quais estavam integrados. Para Bachmann; Knights and Sydow (2001), sem um mínimo de confiança e comprometimento é quase impossível o 
Contribuições para a gestão de redes interorganizacionais: fatores determinantes para a saída de empresas parceiras

estabelecimento e a manutenção de relações organizacionais bem-sucedidas por um longo período. Isto leva a seguinte hipótese de pesquisa:

H6: Quanto menor o nível de confiança e comprometimento entre as empresas parceiras, maior a probabilidade de elas saírem da rede.

\subsubsection{Assimetria de Informação e Oportunismo}

Williamson (1985) aborda que a assimetria da informação entre os atores envolvidos no processo de colaboração era prejudicial para promover a performance das empresas e que ainda gerava à elas um alto custo. Esta variável se refere à apropriação de lucros associados à determinada transação (FIANI, 2002). Este comportamento, de caráter oportunista, existe quando um dos atores atua estrategicamente, buscando concretizar seus próprios interesses em detrimento dos interesses de outros atores e sob a desobediência das normas (WILLIAMSON, 1985). A suposição do oportunismo numa situação em que há assimetrias de informação, isto é, casos em que pessoas ou empresas têm diferentes níveis de conhecimento a respeito de determinada oportunidade ou sobre as circunstâncias de uma negociação, pode aumentar os custos ou diminuir os benefícios da outra parte, que é incapaz de monitorar ou controlar as ações do agente oportunista (BYRNS e STONE, 1996).

Desta maneira, no momento em que as empresas da rede não receberem informações similares e se começar a verificar o comportamento oportunista, a complexidade e a incerteza da situação comercial aumentará (LIMA, 2007), e as firmas começarão a projetar salvaguardas para não serem vítimas uma das outras (WILLIAMSON, 1985), o que faz com que a rede estabeleça rígidos mecanismos de controle. A longo prazo, as firmas que se comportarem de maneira oportunista não encontrarão sócios novos para colaboração, por causa de sua reputação (Keil, 2000). Assim, para Williamson (1985) oportunismo é um conceito central para a teoria dos custos de transação e é uma das causas principais das falhas de mercado e para a continuidade das organizações (PEREIRA et. al., 2010). Fatos como este suportam a assertiva de que a assimetria de informações e o oportunismo podem influenciar as empresas na decisão de se desligarem da relação colaborativa. Tal assertiva é testada pela seguinte hipótese de pesquisa:

H7: O comportamento oportunista dos integrantes tem relação positiva com a saída de empresas da rede.

REAd | Porto Alegre - Edição 78 - N² 2 - maio/agosto 2014 - p. 305-340 
Leander Luiz Klein \& Breno Augusto Diniz Pereira

\subsubsection{Altos Custos da rede}

Sadowski e Duysters (2008) verificaram, em seus estudos, que um dos problemas das redes é o custo que as empresas tem para mantê-las. Tal fator também foi considerado por Pesämaa (2007), ao colocar este fator como uma das desvantagens desse tipo de relação. Do ponto de vista de Jarillo (1998), o pressuposto básico para a continuidade da existência de uma rede de empresas é de que os ganhos provenientes da cooperação sejam superiores, em longo prazo, aos lucros que podem ser obtidos fora da rede. Caso esse fato não se concretize, as empresas buscam opções fora da rede, para manter o mesmo padrão a um menor custo.

Jarillo (1998) acrescenta que duas condições são essenciais: o pertencimento à rede deve prover desempenho superior (resultados maiores para dividir, dada a eficiência da rede), e os mecanismos de divisão dos resultados serem justos. Se essas duas condições forem satisfeitas (desempenho superior e divisão justa), a rede terá maiores possibilidades de ser bem sucedida. Assim, "uma rede está apta a sustentar sua estrutura e permanecer como um mecanismo eficiente para transações interfirmas, enquanto os benefícios econômicos dos parceiros se sobrepuserem aos custos potenciais de gerenciar a aliança" (PARK e UNGSON, 2001, p.47). Caso essa relação não seja positiva, os integrantes da rede julgam os custos da rede como sendo altos e acabam saindo das redes as quais pertenciam. Este fato é testado nesse estudo pela seguinte hipótese de pesquisa:

H8: Os altos custos da rede estão positivamente relacionados à saída de empresas parceiras.

\subsubsection{Assimetria de Investimentos}

A Teoria da Ação Coletiva de Olson (1971) tem como ideia central a formação de grupos movidos por interesses econômicos, com um forte apelo ao interesse próprio. Conforme o próprio autor discorre, "a razão para pertencer a um determinado grupo revela-se pela chance ou possibilidade de conseguir algo através desse pertencer" (OLSON, 1999, p.18). Este conceito surge em decorrência do fato dos indivíduos possuírem diferentes motivos em alcançar o objetivo comum (OLSON, 1999), ou seja, em um grupo, um indivíduo pode-se associar um valor mais alto a certo bem coletivo, estando disposto a investir mais para sua obtenção. No entanto, "nem todos os indivíduos do grupo associam o mesmo valor ao bem, apesar de terem interesse em consumi-lo. Esses indivíduos têm incentivos para não

REAd | Porto Alegre - Edição 78 - N 2 - maio/agosto 2014 - p. 305-340 
Contribuições para a gestão de redes interorganizacionais: fatores determinantes para a saída de empresas parceiras

contribuir, uma vez que o grupo vai fazê-lo de qualquer forma. Eles são os caronas" (PEREIRA, p. 36, 2005).

Além disso, uma importante razão para o desapontamento de muitas firmas com alianças estratégicas se deve à falta de compreensão sobre a dinâmica dos relacionamentos (PEREIRA et al., 2010). As empresas falham em reconhecer em reconhecer as diferentes orientações estratégicas dos sócios (DACIN; HITT; LEVITAS, 1997) e a existência de assimetria de incentivos em investir na relação, a qual inevitavelmente surge à medida que a aliança evolui (PEREIRA et al., 2010). Os objetivos, que antes eram comuns, podem, com o passar do tempo, perder parte do sentido e consequentemente reduzir o interesse de um ou outro participante em cooperar (KHANNA, GULATI e NOHRIA, 1998). Em geral, a cooperação enfraquece e abre caminho para saída de empresas do processo de colaboração quando alguma das partes percebe tratamento injusto ou resultados incompatíveis com sua contribuição. Diante disso, tem-se a seguinte hipótese de pesquisa:

H9: A assimetria de investimentos tem relação positiva com a saída das empresas da rede.

\subsubsection{Individualismo dos integrantes}

A relação da predominância do nível de coletivismo versus individualismo de uma pessoa é uma característica que pode servir para o entendimento das relações por ela estabelecida ou na sua adaptação e permanência no grupo. Argumenta-se que, quanto mais individualista o sujeito for, maior é a sua tendência a agir de forma oportunista. Campos (2006) afirmam que os insucessos de iniciativas em estruturas associativistas devem-se, principalmente, ao fato de um componente do grupo tenta levar vantagem sobre os demais, caracterizando uma visão individualista.

Na visão de Doney, Cannon and Mullen (1998), sujeitos com orientação individualista tendem a interagir de forma competitiva, com baixa lealdade para com os outros e com as organizações parceiras dificultando a formação de relações de confiança. Zand (1972) explica que, em relações de pessoas em grupos (o que se aplica também às redes), determinadas ações aumentam a vulnerabilidade do conjunto, pois se aquele que não está sob o controle do outro abusa de tal vulnerabilidade em troca de um benefício próprio, e o outro não faz o mesmo, ocorre a desilusão, o desentendimento no grupo e a quebra da confiança. Com base nisso elaborou-se a seguinte hipótese de pesquisa:

REAd | Porto Alegre - Edição 78 - N² 2 - maio/agosto 2014 - p. 305-340 
Leander Luiz Klein \& Breno Augusto Diniz Pereira

H10: O individualismo dos integrantes está positivamente relacionado com a saída de empresas da rede.

\subsection{Resultados percebidos da colaboração}

\subsubsection{Imediatismo por resultados}

Uma questão inerente ao oportunismo é a atitude de quebra de acordos, normas e princípios que guiam a rede (EDELMAN et al., 2004). Essa atitude oportunista, geralmente, é motivada pela possibilidade de ganhos num prazo mais curto, ou até em imediato, em detrimento de ganhos futuros, o que impacta na confiança do grupo e aumenta a dificuldade de gestão e coordenação das atividades e a incerteza. Wegner; Zen e Andino (2008) citam como exemplo concreto nas redes de empresas a situação em que um ou mais parceiros decidem quebrar acordos de compra conjunta para obter descontos particulares maiores de outro fornecedor, imediatamente.

No estudo de Klein e Pereira (2012), a partir de uma pesquisa exploratória envolvendo a opinião de sete presidentes de redes de empresas, os pesquisadores identificaram esse mesmo determinante como uma possível causa da saída de empresas de redes. A perspectiva de empresários em auferirem ganhos imediatos ao entrarem em uma rede interorganizacional pode levá-los à frustração e ao abandono da rede, uma vez que, muitas redes, quando formadas, geram retornos aos seus integrantes no médio ou longo prazo. Diante disso, tem-se a seguinte hipótese de pesquisa.

H11: O imediatismo por resultados está positivamente relacionado com a saída de empresas da rede.

\subsubsection{Metas e Objetivos não Alcançados}

O modelo racional-intencional de eficácia organizacional assume que organizações são projetadas para atingir determinados objetivos (ETZIONI, 1964). Portanto, o sucesso da colaboração requer um alinhamento ou compatibilidade de objetivos, bem como o alcance dos mesmos. Para Wegner e Padula (2010, p. 74), a "continuidade da cooperação é condicionada à capacidade de atingir os objetivos propostos e fazer os membros mais competitivos".

Pode-se dizer que muitos problemas em redes ocorrem a partir da constatação de que os objetivos e metas inicialmente propostas não foram correspondidos. Para Pereira et al.,

REAd | Porto Alegre - Edição 78 - N² 2 - maio/agosto 2014 - p. 305-340 
Contribuições para a gestão de redes interorganizacionais: fatores determinantes para a saída de empresas parceiras

(2010), de maneira específica, uma ideia intrínseca nos estudos relacionados à gestão das redes sugere que os conflitos são causados por objetivos organizacionais não alcançados por um membro da aliança. O surgimento de conflitos poderá ocorrer caso um ou mais desses objetivos não sejam alcançados, ocasionando a insatisfação e o desentendimento entre as empresas parceiras e incitando a saída da empresa da rede. Este argumento é testado pela seguinte hipótese de pesquisa:

H12: A saída de empresas da rede ocorre por metas e objetivos organizacionais não alcançados.

\subsubsection{Baixa Aprendizagem Interorganizacional}

Uma perspectiva relacionada à aprendizagem interorganizacional enfatiza que as alianças entre empresas surgem como uma resposta estratégica por organizações às mudanças ambientais que exigem melhoria nas habilidades, conhecimentos e capacidade tecnológica (KOGUT, 1988). Assim, na visão de Somfleth (2011), torna-se evidente a partir da literatura existente que a aprendizagem com os outros indivíduos é uma forma da organização desenvolver o seu negócio tornando-se mais competitiva em um mundo de negócios altamente competitivo e com necessidade de maiores desenvolvimentos. Na visão de Pardini; Santos e Gonçalves (2008) essa aprendizagem não é promovida isoladamente. Para os autores, aprendizagem interorganizacional resulta, ao mesmo tempo, do confronto e da união dos conhecimentos disponíveis por meio das experiências da organização. A aprendizagem é relevante, pois a inovação substantiva exige que os participantes aprendam e se comuniquem uns com os outros permitindo a transformação (HANDLEY et al., 2006).

No processo de construção e na vigência da rede, o não compartilhamento do knowhow constituído e circulante na rede pode levar algumas empresas a não perceberem diferenciais e a agregação de valor pelo processo de cooperação, visto que este é considerado um elemento-chave para desenvolver competências (LARSSON et al., 1998). Isto, aparentemente, estaria relacionado à saída de empresas das redes, fato testado com a seguinte hipótese de pesquisa:

H13: A baixa aprendizagem interorganizacional está positivamente relacionada à saída das empresas da rede.

REAd | Porto Alegre - Edição 78 - № 2 - maio/agosto 2014 - p. 305-340 
Leander Luiz Klein \& Breno Augusto Diniz Pereira

\subsubsection{Redução da Autonomia das Empresas Parceiras}

A colaboração com outra organização é vista por muitos como um processo de destruição da autonomia organizacional. Em qualquer aliança de colaboração, os parceiros inevitavelmente lidam com as tensões acerca da autonomia organizacional e do poder diferencial da relação (BRYSON; CROSBY; STONE, 2006). Quando as organizações estão envolvidas em atividades fronteiras, que atravessam qualquer rede de colaboração, as organizações devem equilibrar o dualismo de ação individual e as preocupações e acordos coletivos (CHEN, 2010).

Em uma parceria eficaz, um colaborador deve destinar parte de um "dia-a-dia" de controle sobre as atividades de sua organização em troca de ganhos de colaboração (CUMMINGS, 1984). Muitas vezes, a rede limita também os acordos com os fornecedores, reduzindo a autonomia das empresas integrantes. No entendimento de Chen (2010), a redução da autonomia organizacional é um resultado negativo da colaboração e susceptível de ser visto como uma ameaça à continuidade da rede. Isso, segundo o autor, levaria as empresas participantes a dedicar menos tempo, recursos e esforços para a continuação da relação, comprometendo a estabilidade e continuidade da rede. Com base nisso, tem-se a seguinte hipótese de pesquisa:

H14: A redução da autonomia dos integrantes da rede é motivo de saída dos mesmos do empreendimento conjunto.

\subsubsection{Falta de Inovação e Geração de Valor}

Para Westerlund e Rajala (2010), há uma relação direta e positiva entre inovação e o processo de colaboração de empresas em rede. Entretanto, quanto a esse aspecto, Pereira (2005) e Ahola (2009) colocam que a queda da relação entre empresas ocorre devido à incapacidade de gerar novos benefícios para seus membros. Nos estudos de Pereira (2005), não foi encontrada nenhuma tentativa mais estruturada para criar novos conhecimentos, visando o benefício coletivo. Nessa situação, as empresas buscam alternativas estratégicas para sair da rede, minimizando os custos e mantendo os benefícios de pertencer a uma rede.

Sem a geração de novos benefícios não há a criação de valor dentro da rede de empresas, motivo que gera desistência do trabalho cooperativo e a consequente falência da rede (HARRIGAN, 1988). Além disso, muitos dos esforços despendidos são difíceis de serem avaliados e, em muitos casos os benefícios, como a melhoria da imagem e o aumento 
Contribuições para a gestão de redes interorganizacionais: fatores determinantes para a saída de empresas parceiras

da credibilidade perante fornecedores, só começam a surgir dentro de cinco a dez anos de vida de rede (PARK; CHEN; GALLAGHER, 2002). Assim, a inovação e a geração de valor são aspectos relevantes no processo colaborativo, além de serem formas de se obter vantagens competitivas e de se manter as empresas na rede. O contrário disso remete a seguinte hipótese de pesquisa:

H15: A falta de inovação e criação de valor para as empresas participantes do empreendimento conjunto está positivamente relacionada à saída das mesmas da rede.

Pode-se verificar que são diversos os fatores que devem receber atenção e serem devidamente observados, desde a formação e durante a vigência da rede. Os subitens deste tópico do trabalho constituem o embasamento teórico e serviram para o desenvolvimento do instrumento de coleta de dados que será descrito no tópico seguinte, no qual será apresentado o método de trabalho utilizado, e os aspectos a ele inerentes, buscando descrever a forma como será realizado o presente estudo.

\section{PROCEDIMENTOS METODOLÓGICOS}

Este trabalho caracteriza-se como uma pesquisa descritiva com uma abordagem quantitativa. Para o alcance do objetivo do trabalho, adotou-se como estratégia de pesquisa de campo a survey, que foi aplicada em diferentes regiões do estado do Rio Grande do Sul, Brasil. Quanto aos momentos em que a pesquisa foi aplicada, este estudo denomina-se como cross-sectional, uma vez que foi aplicado em um único momento no tempo (SAMPIERI, COLLADO e LUCIO, 2006).

A população deste estudo é representada por empresas que se desligaram (saíram) das redes de cooperação às quais estavam vinculadas. A dificuldade encontrada, no entanto, foi o fato de que não se sabe, ao certo, o número de empresas que saíram de redes. Alguns estudos foram feitos na tentativa de verificar esses números. O estudo de Toigo e Alba (2010), por exemplo, realizado no estado do Rio Grande do Sul, Brasil, verificou que $37 \%$ do total de redes formadas foram encerradas. As empresas pertencentes a este grupo fazem parte da população deste estudo, mas, mesmo assim, o total de empresas que desistiram do processo de cooperação ainda não é conhecido. Isto por que há empresas que saíram da rede em que

REAd | Porto Alegre - Edição 78 - N² 2 - maio/agosto 2014 - p. 305-340 


\section{Leander Luiz Klein \& Breno Augusto Diniz Pereira}

estavam inseridas, e, a rede a qual elas pertenciam, ainda está vigorando, e não há uma estimativa exata do número de empresas que saíram de todas as redes. Diante disso, a população de empresas que saíram de redes foi considerada como desconhecida. A amostra da pesquisa caracteriza-se como sendo não probabilística selecionada de forma intencional por acessibilidade. Conseguiu-se uma amostra válida de 140 empresários respondentes por meio da aplicação de uma survey.

Para a coleta de dados, foi utilizado um questionário estruturado com cinco perguntas para cada um dos 15 determinantes (constructos) especificados no referencial teórico deste trabalho. As perguntas foram elaboradas tendo como base a pesquisa teórica realizada pelos autores. Do total de 140 questionários aplicados, 109 deles (77,86\%) foram aplicados pessoalmente pelos pesquisadores em 54 cidades distintas. Os outros $31(22,14 \%)$ questionários foram aplicados por telefone com os empresários que se dispuseram a participar do estudo. A medida utilizada para avaliar as respostas dos empresários para cada conjunto de cinco perguntas dos quinze determinantes (constructos) avaliados foi uma escala do tipo Likert de 1 (discordo totalmente) até 6 (concordo totalmente). As respostas dos empresários, codificadas por meio da escala do tipo Likert de seis pontos, foram transcritas para uma planilha do Excel 2007 para posterior análise no SPSS e AMOS 18.0.

A análise dos dados obtidos foi feita com a aplicação da técnica de Modelagem de Equações Estruturais (MME) (Kline 1998; Hair et al., 2005). O primeiro passo realizado foi avaliar a consistência interna dos determinantes analisados pelo cálculo do Alpha de Cronbach. Nessa etapa, foram eliminadas as variáveis observadas que diminuíam a consistência interna dos determinantes, procurando obter um valor superior a 0,7 para cada um (HAIR et al.,2005). Após esse procedimento, foi feita a média das variáveis observadas para cada determinante, constituindo 15 variáveis latentes de primeira ordem. Estas variáveis constituídas serviram assim para avaliar o objeto de estudo deste trabalho, a 'saída de empresas de redes'(variável latente de segunda ordem) e testar as hipóteses apresentadas no referencial teórico deste trabalho.

O modelo proposto foi validado por meio dos índices de ajuste do modelo global, e a partir da significância e magnitude dos coeficientes de regressão estimados. A medida de significância destes coeficientes foi avaliada através de um Teste $\mathrm{T}$, e coeficientes que não atingiram uma significância de 5\% tiveram suas relações retiradas do modelo. Outra indicação desses coeficientes é o nível das relações causais dos determinantes do modelo com a saída de

REAd | Porto Alegre - Edição 78 - N² 2 - maio/agosto 2014 - p. 305-340 
Contribuições para a gestão de redes interorganizacionais: fatores determinantes para a saída de empresas parceiras

empresas das redes, permitindo, por meio da avaliação dos mesmos, a confirmação ou rejeição das hipóteses da pesquisa. Nos tópicos a seguir, apresentam-se os resultados encontrados nesta pesquisa.

\section{RESULTADOS}

\subsection{Consistência interna dos determinantes do framework proposto}

A mensuração da consistência das variáveis observáveis para validação interna dos construtos foi feita pelo cálculo do Alpha de Cronbach. A Tabela 1 exibe o valor do Alpha de Cronbach para cada construto, o número de itens (variáveis observadas) que medem o mesmo, bem como quais as variáveis que foram eliminadas.

Conforme pode ser observado na Tabela 1, o único constructo que ficou abaixo do padrão de fidedignidade, indicado por Hair et al., (2005), foi o construto 'Laços Sociais Anteriores' (0,696), no entanto, este foi considerado aceitável por ser um valor perto do padrão estipulado. Pode-se verificar, também, que da maioria dos determinantes foi retirada uma ou duas variáveis para adquirir o nível de consistência estipulado como aceitável. A partir do conjunto de cálculos, foi possível considerar como fidedignas as variáveis observadas propostas para a mensuração dos determinantes deste estudo. Validados os construtos, efetua-se, a seguir, a aplicação da técnica de modelagem de equações estruturais para identificar a influência de cada um dos construtos na 'saída de empresas das redes' e avançar no entendimento e conhecimento sobre o tema.

REAd | Porto Alegre - Edição 78 - N² 2 - maio/agosto 2014 - p. 305-340 
Leander Luiz Klein \& Breno Augusto Diniz Pereira

Tabela 1 - Consistência Interna dos Construtos

\begin{tabular}{|c|c|c|c|}
\hline DETERMIANTE/ CONSTRUTO & $\begin{array}{l}\text { CRONBACH'S } \\
\text { ALPHA }\end{array}$ & $\begin{array}{l}\text { NÚMERO DE } \\
\text { ITENS }\end{array}$ & $\begin{array}{l}\text { VARIÁVEIS } \\
\text { ELIMINADAS }\end{array}$ \\
\hline Seleção de Parceiros não estruturada & 0,743 & 5 & ---- \\
\hline Laços Sociais Anteriores Fracos & 0,696 & 5 & ----- \\
\hline Falta de Legitimação às Empresas & 0,914 & 5 & ----- \\
\hline Gestão Individualizada & 0,858 & 5 & ----- \\
\hline Baixa Troca de Recursos & 0,896 & 4 & Variável 25 \\
\hline $\begin{array}{l}\text { Falta de Confiança e } \\
\text { Comprometimento }\end{array}$ & 0,797 & 4 & Variável 29 \\
\hline $\begin{array}{l}\text { Assimetria de Informação e } \\
\text { Oportunismo }\end{array}$ & 0,788 & 3 & Variáveis 31 e 34 \\
\hline Altos Custos da Rede & 0,804 & 4 & Variável 36 \\
\hline Assimetria de Investimentos & 0,721 & 3 & Variáveis 41 e 42 \\
\hline Metas e Objetivos Não Alcançados & 0,856 & 4 & Variável 49 \\
\hline $\begin{array}{lcc}\text { Baixa } & \text { de } & \text { Aprendizagem } \\
\text { Interorganizacional } & \end{array}$ & 0,906 & 5 & ----- \\
\hline $\begin{array}{l}\text { Redução da Autonomia } \\
\text { Empresas Parceiras }\end{array}$ & 0,798 & 4 & Variável 57 \\
\hline Pouca Geração de Valor e Inovação & 0,833 & 4 & Variável 65 \\
\hline Imediatismo por Resultados & 0,927 & 5 & ----- \\
\hline Individualismo dos Integrantes & 0,735 & 4 & Variável 75 \\
\hline
\end{tabular}

\subsection{Aplicação da técnica de Modelagem de Equações Estruturais}

\subsubsection{Medidas de ajuste do Modelo Proposto}

Após ter sido calculada a média do conjunto de variáveis observadas para cada determinante, inseriu-se estes no programa AMOS 18.0 para avaliar a relação destes com a variável latente de segunda ordem 'Saída de Empresas de Redes'. Ressalta-se, no entanto, que na estimação do primeiro diagrama do Modelo Proposto, os resultados encontrados não foram adequados. Primeiramente, o valor da significância para os coeficientes dos determinantes 'Assimetria de Investimentos' e 'Redução da autonomia das empresas parcerias' foram, respectivamente, 0,101 e 0,188, não sendo assim significativos aos 5\% (medida adotada como limite de significância). Em virtude disso, efetuou-se a estratégia de aprimoramento do Modelo Proposto. Essa estratégia de aprimoramento consiste na retirada dos coeficientes de regressão não significativos e na adição de covariâncias, entre os determinantes, propostas pelo relatório de modificações do sofware AMOS 18, que inicialmente não foram previstas. 
Contribuições para a gestão de redes interorganizacionais: fatores determinantes para a saída de empresas parceiras

Estas modificações, só foram incorporadas nos casos que tivessem argumentação teórica que as justificassem.

\subsubsection{Aprimoramento do Modelo Proposto}

O primeiro procedimento realizado para o aprimoramento do modelo consistiu na retirada dos dois construtos que não apresentavam coeficientes com relação significativa. Essa retirada implicou na reestimação do modelo, uma vez que aquela repercutia em modificações nos coeficientes e significâncias dos demais determinantes do modelo.

Em seguida, efetuou-se a avaliação das modificações sugeridas pelo programa AMOS 18 para ajuste dos índices e validação do modelo. Pela análise dessas modificações, julgou-se conveniente a adoção das seguintes covariâncias:

1- Seleção dos Parceiros não estruturada (e1) e Metas e Objetivos Não Alcançados (e10);

2- Gestão Individualizada (e4) e Altos Custos da Rede (e8);

3- Baixa Troca de Recursos (e5) e Baixa Aprendizagem (e11);

4- Falta de Confiança e Comprometimento (e6) e Assimetria de Informação e Oportunismo (e7);

5- Baixa Aprendizagem Interorganizacional (e11) e Individualismo dos Integrantes (e15).

Após a retirada das relações não significativas e da inserção das covariâncias sugeridas pelo sistema e suportadas com aporte teórico, o Modelo Resultante apresentou os índices de ajuste apresentados na Tabela 2.

Tabela 2 - Índices de ajuste do Modelo Resultante

\begin{tabular}{l|l}
\hline ÍNDICES & Valor \\
\hline Qui-quadrado / Graus de Liberdade & 2,016 \\
\hline GFI - Goodness of Fit & 0,885 \\
\hline CFI - Comparative Fit Índex & 0,902 \\
\hline NFI - Normed Fit Índex & 0,826 \\
\hline IFI - Incremental Fit Índex & 0,904 \\
\hline RMR - Root Mean Square Residual & 0,086 \\
\hline RMSEA - Root Mean Squared Error of Approximation & 0,085 \\
\hline \multicolumn{2}{c}{ Fonte: Elaborada pelos autores }
\end{tabular}

A verificação dos índices da Tabela 2 mostra uma apropriação do modelo. A relação qui-quadrado/graus de liberdade atingiu o valor de 2,016 ficando abaixo de 3,0, limite REAd | Porto Alegre - Edição 78 - N 2 - maio/agosto 2014 - p. 305-340 
Leander Luiz Klein \& Breno Augusto Diniz Pereira

considerado adequado por Kline (1998) e Hair et al. (2005). As medidas GFI e NFI ficaram levemente abaixo do padrão aceitável de 0,9 , e as medidas CFI e IFI ficam acima, indicando assim que o ajuste do modelo é adequado. Já em relação aos índices RMR e RMSEA, verificou-se também uma melhora, se comparado como o modelo anterior. O RMR ficou abaixo do limite máximo indicado de 0,1 , enquanto que o RMSEA ficou levemente acima do limite de 0,08, mas considerado adequado pela pequena distância do limite aceito. Estes dois índices indicam que os resíduos são adequados para as estimativas das relações. Dessa forma, verifica-se que a retirada das relações não significativas e a inserção das covariâncias indicadas pelo software permitiram uma melhora substancial nos valores de ajustamento do Modelo Resultante. A figura 2 mostra o diagrama do Modelo Resultante.

Para a visualização dos pesos (coeficientes) de cada determinante com a variável latente 'Saída de Empresas das Redes' e as significâncias de cada relação elaborou-se a Tabela 3, na qual são apresentados estes dados do Modelo Resultante.

A partir da Tabela 3, pode-se verificar que os coeficientes padronizados das relações são significativos estaticamente (1 e $5 \%$ ). A medida destes coeficientes permite a análise das hipóteses de pesquisa originalmente formuladas nos tópicos anteriores deste trabalho, que são detalhadas e discutidas na sequencia do trabalho. A magnitude de cada relação permite, também, verificar quais dos determinantes mais impactam na saída de empresas de redes interorganizacionais, com base nos dados obtidos nessa pesquisa.

REAd | Porto Alegre - Edição 78 - N² 2 - maio/agosto 2014 - p. 305-340 
Contribuições para a gestão de redes interorganizacionais: fatores determinantes para a saída de empresas parceiras

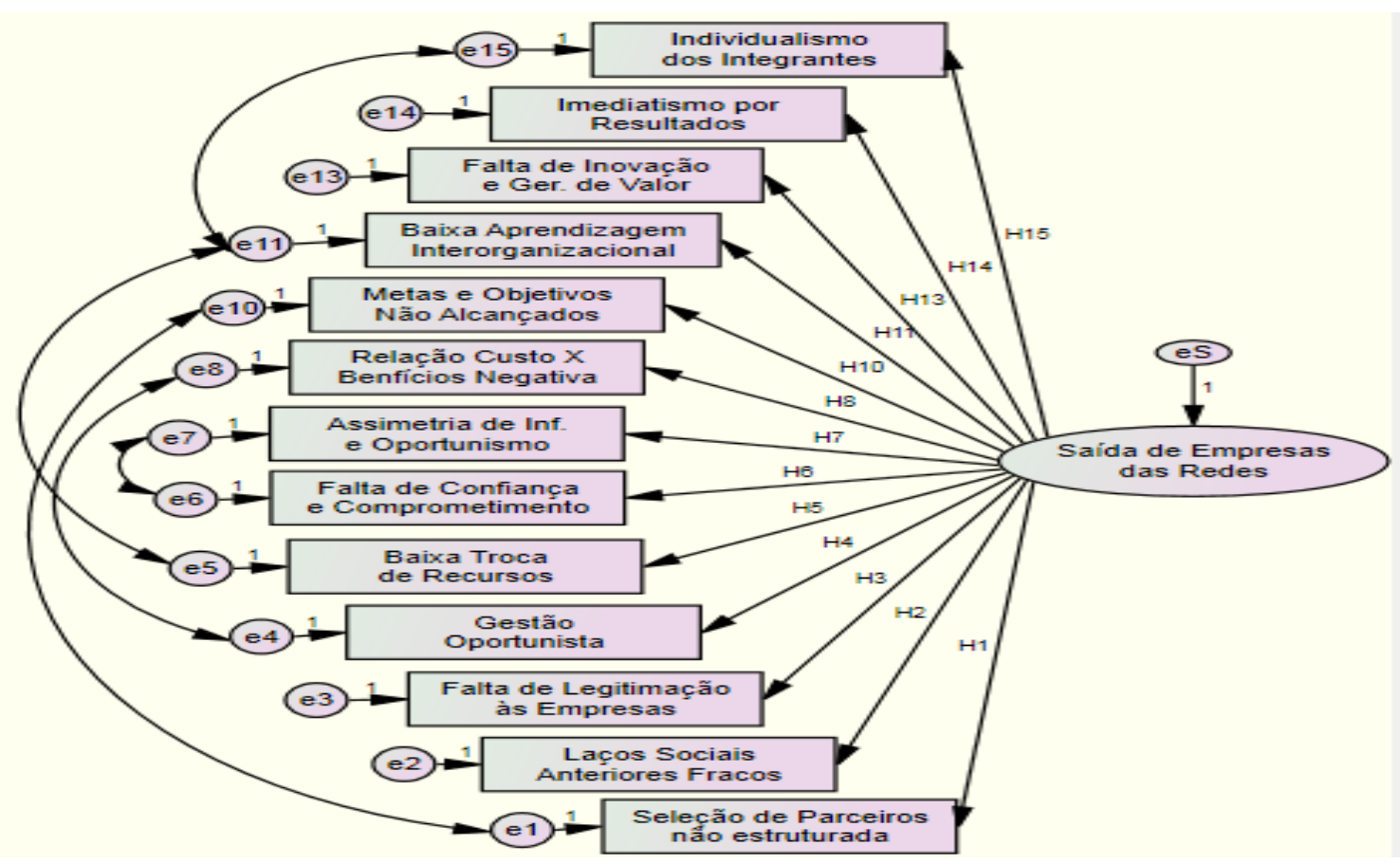

Figura 2 - Diagrama do Modelo Resultante Fonte: AMOS 18

Tabela 3 - Coeficientes padronizados e significâncias das relações do Modelo Resultante

\begin{tabular}{|c|c|c|c|c|c|}
\hline \multicolumn{3}{|l|}{ RELAÇÕES } & Coef. & Valor de Z & Sig. \\
\hline Seleção de Parceiros não estruturada & $<---$ & Saída Empresas & 1 & & $\mathrm{a}$ \\
\hline Laços Sociais Anteriores Fracos & $<---$ & Saída Empresas & 0,264 & 2,75 & $* *$ \\
\hline Falta de Legitimação às Empresas & $<---$ & Saída Empresas & 0,535 & 4,65 & $* * *$ \\
\hline Gestão Individualizada & $<---$ & Saída Empresas & 0,522 & 4,54 & $* * *$ \\
\hline Baixa Troca de Recursos & $<--$ & Saída Empresas & 0,608 & 4,99 & $* * *$ \\
\hline $\begin{array}{l}\text { Falta de } \\
\text { Comprometimento }\end{array}$ & $<---$ & Saída Empresas & 0,641 & 5,13 & $* * *$ \\
\hline $\begin{array}{l}\text { Assimetria de Informação } \\
\text { Oportunismo }\end{array}$ & $<---$ & Saída Empresas & 0,494 & 4,42 & $* * *$ \\
\hline Altos Custos da Rede & $<---$ & Saída Empresas & 0,749 & 4,49 & $* * *$ \\
\hline Individualismo dos Integrantes & $<--$ & Saída Empresas & 0,136 & 1,49 & $* *$ \\
\hline Imediatismo por Resultados & $<---$ & Saída Empresas & $-0,357$ & $-3,52$ & $* * *$ \\
\hline Metas e Objetivos Não Alcançados & $<---$ & Saída Empresas & 0,841 & 5,01 & $* * *$ \\
\hline $\begin{array}{lcc}\text { Falta } & \text { de } & \text { Aprendizagem } \\
\text { Interorganizacional } & \\
\end{array}$ & $<---$ & Saída Empresas & 0,503 & 4,47 & $* * *$ \\
\hline Pouca Geração de Valor e Inovação & $<--$ & Saída Empresas & 0,716 & 5,41 & $* * *$ \\
\hline
\end{tabular}

Fonte: Elaborada pelos autores

Nota:***; ** significativos a $1 \%$ e $5 \%$ respectivamente

a - valor de $\mathrm{z}$ não calculado por que este parâmetro foi arbitrariamente fixado em 1,0

REAd | Porto Alegre - Edição 78 - N² - maio/agosto 2014 - p. 305-340 
Leander Luiz Klein \& Breno Augusto Diniz Pereira

\subsubsection{Análise do Modelo Resultante}

Das quinze hipóteses propostas, duas delas (H9 e H14), foram eliminadas do Modelo Resultante por não apresentarem significância estatística, conforme já mencionado anteriormente. Já, partindo-se da análise das relações que tiveram significância estatística, verificou-se, pela inquirição do sinal dos coeficientes, a rejeição de apenas uma hipótese (H11), que se refere ao Imediatismo por Resultados e Expectativa de Ganhos de Curto Prazo. Este determinante está relacionado com a expectativa dos empresários em obterem resultados e retornos imediatos ao ingressarem em uma rede. É sabido que, na maioria das redes de cooperação, os resultados das atividades e empreendimentos conjuntos, muitas vezes, aparecem somente a médio e longo prazo. Assim, caso os empresários ingressem nas redes com a expectativa de ganhos imediatos, dificilmente estes permanecerão nesses arranjos colaborativos. No entanto, nesse trabalho, os resultados não suportaram a hipótese levantada, e verificou-se o Imediatismo por Resultados e Expectativa de Ganhos de Curto Prazo não é um aspecto determinante para saída de empresas de redes de cooperação.

As demais doze hipóteses propostas nesse trabalho foram aceitas. Dentre elas, verificou-se que, pela análise da magnitude dos coeficientes das relações, o determinante que mais impactou na saída de empresas de redes foi 'Metas e Objetivos Não Alcançados', referente à hipótese H12. Este fato vai ao encontro do entendimento de Wegner e Padula (2010) sobre o assunto. Estes autores mencionam que a continuidade da cooperação está condicionada à capacidade da rede atingir os objetivos propostos e tornar os membros mais competitivos. De fato, se os objetivos propostos na formação de um empreendimento conjunto desse tipo não estiverem sendo alcançados, será consequência disso, a avaliação negativa das empresas em relação a esse arranjo e sua saída do mesmo. Outro fato que se deve considerar é que o surgimento de conflitos poderá ocorrer caso um ou mais dos objetivos traçados não sejam atingidos, ocasionando a insatisfação e o desentendimento entre as empresas parceiras e incitando a saída das empresas da rede.

A discussão feita no parágrafo anterior tem relação com a hipótese H8, aceita neste trabalho. Esta hipótese se refere à avaliação de que os custos que advinham da manutenção da empresa na rede eram altos e que estes superavam os retornos obtidos pela atuação cojunta. Conforme destacado anteriormente, para a integração de empresas em rede são exigidos custos (investimentos de cada parceiro) aos quais as empresas devem se comprometer e investir (ADLER e KWON, 2002). Para que este processo gere uma relação custo X benefício

REAd | Porto Alegre - Edição 78 - N² 2 - maio/agosto 2014 - p. 305-340 
Contribuições para a gestão de redes interorganizacionais: fatores determinantes para a saída de empresas parceiras

positiva para cada integrante, é necessário que os benefícios econômicos dos parceiros se sobreponham aos custos potenciais de gerenciar a aliança (PARK e UNGSON, 2001). Ora, uma vez que os objetivos propostos no desenvolvimento das redes não estejam sendo alcançados, fica difícil elas proporcionarem retornos que superem os investimentos feitos pelos integrantes, e dessa forma eles decidem por se retirarem das redes.

Outro determinante cuja magnitude do seu coeficiente foi expressiva, em relação aos demais, foi a 'Falta de Inovação e Geração de Valor' (hipótese H15). Estudos anteriores, como os de Pereira (2005) e Ahola (2009), salientam a dificuldade da rede em gerar novos benefícios para seus integrantes ou em inovar. Essa dificuldade gera problemas para a manutenção das redes e afasta a satisfação dos integrantes. Para Westerlund e Rajala (2010), há uma relação direta e positiva entre inovação e o processo de colaboração de empresas em rede. No entendimento de Pereira et al. (2010), apesar de as redes horizontais serem constituídas, em muitos casos, por outros motivos, a inovação torna-se o propulsor da sustentabilidade desses empreendimentos. Caso a rede não gere diferenciais aos seus integrantes e acrescente valor a suas atividades, as empresas passarão a questionar o arranjo cooperativo, e caso não haja uma relação custo $\mathrm{X}$ benefício positiva, muitas delas decidem por saírem da rede.

O problema destacado no parágrafo anterior tem relação com o fato de existir nas redes uma baixa troca de recursos entre os integrantes. Esta hipótese (H5) foi confirmada com os dados desse estudo como sendo mais um determinante para a saída de empresas de redes. A baixa troca de recursos entre os participantes da rede inibe o acesso a diferenciais como o conhecimento tácito, habilidades complementares, novas tecnologias e mercados, a possibilidade de fornecer maior gama de produtos e serviços, e inclusive a própria inovação e geração de valor. Para Pereira et al. (2010) a criação de novos conhecimentos se dará pela ação de todos os atores envolvidos no ambiente da rede, sendo um compromisso estratégico de todos. Caso essa interação e troca não ocorra, o estabelecimento de alianças estratégicas com outras empresas deixa de ser um diferencial em relação ao "trabalhar sozinho" (CHEN, 2010), e as empresas acabam saindo.

Ressalta-se, no entanto, que as dificuldades inerentes e a não execução de muitas das atividades, ações e trocas conjuntas se devem a falta de confiança e comprometimento. Muitos autores como Sadowski e Duysters (2008), Bachmann; Knights and Sydow (2001), 
Leander Luiz Klein \& Breno Augusto Diniz Pereira

Uzzi (1996), Verschoore e Balestrin (2008), Klein e Pereira (2012), Fryxell; Dooley e Vryza (2002), Koza e Lewin (2000), Tiwana (2008), entre outros destacam em seus trabalhos a importância do comprometimento e da confiança entre os parceiros da rede para a efetividade da colaboração. A falta desses dois aspectos pode ser tornar uma barreira para as trocas entre os agentes da rede (empresários e stakeholders) e para a efetividade do aprendizado interorganizacional e da inovação. Pode ser também, uma via para atitudes oportunistas de alguns integrantes. Nesse artigo, a falta de confiança e comprometimento foi confirmada como um determinante para saída de empresas de redes pela aceitação da hipótese H6.

A aceitação da hipótese da baixa de aprendizagem interorganizacional (H13) se deve, muitas vezes, em virtude da falta de confiança e comprometimento discutida anteriormente. Larson et al. (1998) descrevem que a falta de confiança pode ser uma barreira para a criação do conhecimento e para a efetividade do aprendizado interorganizacional. Desta forma, a perspectiva de que as redes permitem que as organizações explorem e assimilem novos recursos e competências, essenciais para seus contextos organizacionais, deixa de ser concretizada. Isso repercute na baixa inovação e geração de valor, pois as empresas não agregam novas formas de implementação recursos e adaptação ao seu uso e às novas situações que são identificadas, e, assim, as redes não agregam valor e diferenciais aos seus integrantes.

Em alguns casos, os problemas identificados até aqui, tem relação com um determinante dos antecedentes para colaboração. Refere-se à hipótese H1, que suporta a relação positiva entre a Seleção de Parceiros não estruturada e a Saída de Empresas de Redes. Pode-se dizer que, mesmo que uma empresa tenha interesse e esteja disposta a cumprir com as regras estabelecidas pela rede, ela pode ter limitações em participar do grande grupo. Caso essa empresa ingresse no arranjo sem observar os critérios de seleção, existe a possibilidade desta não permanecer na rede, uma vez que estes critérios servem para avaliar a congruência destes com os demais integrantes da rede. Este resultado vai ao encontro de autores como Galbraith (1998); Easton (1997); Child e Faulkner (1998); Dekker (2004); Dyer e Singh (1998); Dyer e Chu (2003) que mencionam a importância da adequada seleção de parceiros para uma compatibilidade e congruência entre os mesmos.

A Seleção de Parceiros não estruturada testada e confirmada na hipótese H1 está intimamente ligada a outros problemas e determinantes que geram a saída de empresas das redes. Em seus estudos, Moeller (2010) avaliou a relação da seleção de parceiros com os

REAd | Porto Alegre - Edição 78 - N² 2 - maio/agosto 2014 - p. 305-340 
Contribuições para a gestão de redes interorganizacionais: fatores determinantes para a saída de empresas parceiras

níveis de confiança, comprometimento e oportunismo com o desempenho da rede. O autor verificou uma associação positiva entre esses aspectos. Já quanto ao oportunismo dos integrantes (H7) vale ressaltar a relação oposta com a confiança. Nas ações coletivas, oportunismo e confiança aparecem juntos, mas como vetores opostos, ou seja, quanto maior a confiança, menor o oportunismo. Se a confiança entre os agentes for superior ao oportunismo de cada indivíduo, as negociações e atividades conjuntas tendem a ocorrer. Enquanto o oportunismo é um comportamento individual que depende da decisão pessoal de cada indivíduo, a confiança sempre envolve uma decisão, no mínimo, bilateral.

Com relação à aceitação da hipótese H4 sobre a gestão individualizada, verifica-se que esta, aparentemente, não é usada como forma de agilizar e dinamizar as decisões relativas as atividades e ações da rede. Quando a gerência da rede toma decisões de forma a buscar, em primeiro lugar, a realização e a efetivação de suas próprias necessidades em detrimento dos objetivos conjuntos da rede, podem ser geradas insatisfações entre os integrantes. Este resultado diverge dos estudos realizados por Wegner e Padula (2010), que envolvem redes varejistas na Alemanha. Nesse estudo os autores citam que o aumento na centralização do processo de tomada de decisões é uma clara tendência entre as redes alemãs, o que proporciona agilidade ao processo, mas não significa que as decisões sejam impostas, de forma a prejudicar os parceiros.

Ainda, estudos de governança de Theurl (2005) descrevem que a rede deve ser adaptada e definida de maneira que a agilidade e a flexibilidade necessárias para a tomada de decisão sejam garantidas, tentando satisfazer as condições de continuidade da rede e geração de valor a seus integrantes.

A aceitação das hipóteses H2 e H3 vêm a corroborar com os estudos de Granovetter (1985) e Pëssama (2007), respectivamente. O primeiro autor argumenta que o comportamento econômico dos agentes é afetado por estruturas sociais que são construídas através do tempo, o que pode delinear a permanência ou saída da organização do empreendimento conjunto, a rede. Já o segundo autor, se reporta à falta de legitimação organizacional dos parceiros da rede como uma das desvantagens do processe colaborativo.

Por fim, constatou-se a aceitação da hipótese H10 referente ao individualismo dos integrantes como aspecto influenciador da saída de empresas da rede. Triandis (1995) menciona que a pessoa individualista tende a agir de forma autônoma em relação ao grupo e a 
Leander Luiz Klein \& Breno Augusto Diniz Pereira

busca liberdade para adotar comportamentos e atitudes que satisfaçam seus desejos sem que necessite da aprovação de terceiros. Esse comportamento, no entanto, restringe a atuação conjunta e a harmonia do grupo, gerando conflitos negativos que não agregam e não geram ganhos aos participantes.

Destaca-se que o desafio da gestão dos relacionamentos interorganizacionais está associado à obtenção de informações sobre competências requeridas, necessidades, confiabilidade e demais atributos dos potenciais parceiros. Mais especificamente, compreender como selecionar os parceiros, como se dividem e se desenvolvem novos conhecimentos, como aumentar o nível de interação entre os parceiros e como as empresas inseridas em redes socializam seu know-how pode auxiliar, em primeiro lugar, no alcance dos objetivos propostos, e segundo, a conseguir patamares superiores de competitividade e a minimização de conflitos e desarticulações entre os integrantes, e sua possível saída.

\section{CONSIDERAÇÕES FINAIS}

No presente estudo, buscou-se verificar e compreender os determinantes que levaram as empresas a retirarem-se das redes das quais participavam. Identificou-se que existem aspectos fundamentais a serem observados já na formação das redes interorganizacionais (antecedentes) que se relacionam com outros fatores na dinâmica das redes (processos e resultados de colaboração) e possibilitam às organizações tomarem medidas proativas para tratar problemas potenciais na formação e funcionamento de redes interorganizacionais.

Para responder ao objetivo do trabalho, foi elaborado e testado o Modelo dos Determinantes da Saída de empresas de Redes, a partir do qual, obteve-se como resultado doze construtos validos e com hipótese aceitas para explicar por que as empresas saem das redes. $\mathrm{Na}$ analise do modelo, verificou-se que a magnitude dos coeficientes de alguns determinantes foi maior. Destacam-se os seguintes: 'Metas e Objetivos Não Alcançados', 'Altos Custos para se Manter na Rede' e 'Pouca Inovação e Geração de Valor'. A estes aspectos a administração das redes deve destinar especial atenção, pois revelam as principais necessidades e condições para os empresários permanecerem nesses arranjos. No entanto, a avaliação negativa destes determinantes provavelmente tem relação com outros fatores identificados nessa pesquisa, como a 'Falta de Confiança e Comprometimento' e a 'Seleção 
Contribuições para a gestão de redes interorganizacionais: fatores determinantes para a saída de empresas parceiras

de Parceiros não estruturada' que acabam repercutindo na avaliação negativa de outros determinantes, e em conjunto incidem na saída de empresas de redes.

As interações proporcionadas pelas ações colaborativas entre empresas são caracterizadas por múltiplas dimensões, incluindo a decisão conjunta da administração, os recursos combinados, a troca de informações e competências dentre outros fatores, como apresentado no Framework proposto. Os contatos que os atores estabelecem levam ao desenvolvimento de seu capital social, criando fluxos informacionais e a combinação de conhecimentos sobre o mercado, estratégias, concorrentes, tecnologias e processos, que podem ser utilizados em benefício das empresas envolvidas e potencializar o desempenho. No entanto, a dificuldade que impera sobre as estruturas de governança das redes são as possíveis disfunções oriundas das decisões e formas de gestão das redes, e como estas poderiam ser evitadas, ou ao menos, amenizadas.

Nesse sentido, os questionamentos centrais estão em entender até que ponto uma empresa considera estar inserida em uma rede como vantajoso, quanto ela investe na relação (em termos de recursos: financeiros, pessoal e tempo) e, de que forma as redes podem desenvolver procedimentos e rotinas para diminuir o impacto negativo dos determinantes identificados nesse trabalho.

Ressalta-se que, para as organizações inseridas em redes e que, para própria gestão delas, o desafio é a criação de mecanismos para que se tenha mais controle sobre aspectos subjetivos do desenvolvimento desses arranjos. Pode-se, por exemplo, avaliar de forma mais objetiva os laços sociais anteriores e a seleção de empresas para o arranjo além dos critérios a serem utilizados. Nessa fase inicial, existe uma maneira de avaliar mais objetivamente a confiança e o comprometimento dos futuros parceiros? Estes fatores acabam por delinear a continuidade da rede e a satisfação de empresas no arranjo. A avaliação negativa auferida com maior magnitude em determinantes dos Resultados percebidos da colaboração tem sua origem na inobservância de determinantes chaves na constituição da rede.

As contribuições dessa pesquisa estão subordinadas a algumas limitações metodológicas que são apresentadas para um maior entendimento das possíveis implicações dos resultados obtidos. Primeiramente, com relação à validação do modelo, cabe ressaltar que a validação dos constructos não foi realizada pela aplicação da fatorial confirmatória. Isto remete a não avaliação e peso de cada variável observada separadamente para formação de

REAd | Porto Alegre - Edição 78 - N² 2 - maio/agosto 2014 - p. 305-340 
Leander Luiz Klein \& Breno Augusto Diniz Pereira

uma variável latente (construto). A utilização deste procedimento implicaria em limitações amostrais para a estimação do modelo. Segundo, o modelo encontrado retrata uma relação causal para uma determinada amostra, necessitando de replicações para ser consolidado.

$\mathrm{O}$ estudo a respeito desse assunto em redes remete a algumas questões como: a aparente inobservância ou inexistência de critérios seleção dos parceiros é um fator que condicionou outros aspectos negativos (problemas) para as redes? Até que ponto as empresas estão dispostas a investir em redes? Como a rede pode proporcionar ganhos de cunho social que compensem os investimentos realizados? Estudos que avancem nessas questões devem ser desenvolvidos para aumentar a compreensão sobre o assunto e as possibilidades de sucesso desse tipo de empreendimento, em especial no que diz respeito àqueles formados por empresas de pequeno porte, que, geralmente, possuem maiores dificuldades na gestão de suas atividades.

Por conseguinte, sugerem-se estudos de caso realizados com redes de distintos ramos de atividade para verificar possíveis diferenças entre elas. Isto poderia dar validade aos resultados encontrados e complementar/corroborar com as conclusões alcançadas, incidindo no avanço da teoria. Finalmente, sugere-se a replicação do modelo encontrado, como resultado final do estudo, com outras amostras, pois este não é necessariamente a única representação da realidade.

\section{REFERÊNCIAS}

ADLER, P.; KWON, W. Social capital: Prospects for a new concept. Academy of Management Review, v.23, n.1, p.15-22, 2002.

ALBERS, S. The design of Alliance Governance Systems. Köln: Kölner Wissenschaftsverlag, 2005.

AHOLA, T. Efficiency in Project Networks: The role of inter-organizational relationships in project implementation. Unpublished Doctoral Thesis, Helsinki University of Technology, Finland, 2009.

ANDERSON, E.; LODISH, L.; WEITZ, B. Resource Allocation Behavior in Conventional Channels. Journal of Marketing Research, v.24, p.85-97, 1987. 
Contribuições para a gestão de redes interorganizacionais: fatores determinantes para a saída de empresas parceiras

BACHMANN, R.; KNIGHTS, D.; SYDOW, J. Trust and control in organizational relations. Organization Studies, v. 22, n. 2, p. 337-365, 2001.

BRYSON, J. M.; CROSBY, B. C.; STONE, M. M. The Design and Implementation of CrossSector Collaborations: Prepositions from the Literature. Public Administration Review, v.66,Special issue, p.44-55, 2006.

BYRNS, R.; STONE, G., JR. Microeconomia. São Paulo: Makron Books, 1996. CHAO, C. Y. Decision-making biases in the alliance life cycle: Implications for alliance failure. Management Decision, v. 49, n. 3, p. 350-364, 2011.

CHEN, B. Antecedents or Processes? Determinants of Perceived Effectiveness of Interorganizational Collaborations for Public Service Delivery. International Public Management Journal, v.13, n.4, p.381-407, 2010.

CHILD, J., FAULKNER, D.. Strategies of cooperation: managing alliances, network and joint ventures. New York: Oxford University Press, 1998.

CHILE, T. H.; McMACKIN, J. F. The Integrating Variable: Risk Preferences, Trust, and Transaction Cost Economics. Academy of Management Review, v.21, p.73-96, 1996.

CAMPOS. J. P. Ações associativistas entre pequenas empresas: evidências, formulação e execução. 2006, 143 f. Dissertação (Mestrado em Eng. Mecânica) Universidade Estadual de Campinas, Campinas, 2006.

CORSTEN, D.; GRUEN, T.; PEYINGAUS, M. The effects of supplier-to-buyer identification on operational performance - An empirical investigation of inter-organizational identification in automotive relationships. Journal of Operations Management, v.29, p.549-560, 2011.

CUMMINGS, T. Trans organizational Development. Research in Organizational Behavior, v.6, p.367-422, 1984.

DACIN, M.; HITT, M.; LEVITAS, E. Selecting partners for successful international alliances: Examination of U.S. and Korean firms. Journal of World Business, v.32, n.1, p.316, 1997.

REAd | Porto Alegre - Edição 78 - N² 2 - maio/agosto 2014 - p. 305-340 
Leander Luiz Klein \& Breno Augusto Diniz Pereira

DEKKER, H. C. Control of inter-organizational relationships: evidence on appropriation concerns and cooperation requirements. Accounting, Organizations and Society, v. 29 n. 1, p. 27-49, 2004.

DONEY, P. M.; CANNON, J.; MULLEN, M.. Understanding the influence of national culture on the development of trust. Academy of Management Review, v. 23, n.3, p. 601-620, 1998.

DOUMA, M., BILDERBEEK, J., IDENBURG, P., LOOISE, J., Strategic alliances. Managing the dynamics of fit. Long Range Planning, v.33, p.579-598, 2001.

DYER, J. H.; CHU, W. The role of trustworthiness in reducing transaction costs and improving performance: Empirical evidence from the United States, Japan, and Korea. Organization Science, v.14, n.1, p.57-68, 2003.

DYER, H. J.; SINGH, H. H. The Relational View: Cooperative Strategy and Sources of Interorganizational Competitive Advantage. Academy of Management Review, v.23, n.4, p.660-679, 1998.

DWYER, F. R.; SCHURR, P.; OH, S. Developing Buyer-Seller Relationships. Journal of Marketing, v.51, p.11-27, 1987.

EASTON, G. "Industrial networks: a review". In Ford, D. (Ed.), Understanding Business Markets: Interaction, Relationships and Networks. London: Academic Press, 1997.

EDELMAN, L., BRESNAN, M., NEWELL, S., SCARBRUGH, H.; SWAN, J. The benefits and pitfalls of social capital: Empirical evidence of two organizations in the United Kingdom. British Journal of Management, v.15(Special Issue), p.59-69, 2004.

ETZIONI, A. A. Modern Organizations. Englewood Cliffs, NJ: Prentice Hall, 1964.

FIANI, R. Teoria dos Custos de Transação. In: KUPFER, D.; HASENCLEVER, L. Organização Industrial. 2. ed. Rio de Janeiro: Campus, 2002.

FRYXELL, G. E.; DOOLEY, R.S.; VRYZA, M. After the Ink Dries: The Interaction of Trust and Control in Us-Based International Joint Ventures. Journal of Management Studies, v.39, n.6, September, 2002. 
Contribuições para a gestão de redes interorganizacionais: fatores determinantes para a saída de empresas parceiras

GALBRAITH, J.R. Designing the networked organization. In Mohrmann, S.A., Galbraith, J.R. and Lawler, E.E. (Eds), Tomorrow's Organization: Crafting Winning Capabilities in a Dynamic World. Jossey-Bass, San Francisco, CA, p. 76-102, 1998.

GRADDY, E., CHEN, B. Influences on the Size and Scope of Networks for Social Service Delivery. Journal of Public Administration Research and Theory, v.16, n.4, p.533-552, 2006.

GRANOVETTER, M. Economic action and social structure: the problem of Embeddedness. American Journal of Sociology, v.91, n.3, 1985.

GULATI, R. Does Familiarity Breed Trust? The Implications of Repeated Ties for Contractual Choice in Alliances. Academy of Management Journal, v.38, n.1, p.85-112, 1995.

HAIR JR., J. F.; BARRY, B.; MONEY, A. H.; SAMOUEL, P. Fundamentos de métodos de pesquisa em administração. Porto Alegre: Bookman, 2005.

HANDLEY, K.; STURDY, A.; FINCHAM, R.; CLARK, T. A. R. Within and beyond communities of practice: making sense of learning through participation, identity and practice. Journal of management studies, v. 43, n. 3, p. 641-653, 2006.

HARRIGAN, K.R. Joint ventures and competitive strategy. Strategic Management Journal, v.12, p.83-103, 1988.

HASTINGS, C. The new organization: Growing the culture of organizational networking, London: McGraw-Hill, 1996.

HITT, M. A.; LEVITAS, E.; ARREGLE, J.; BORZA, A. Partner Selection in Emerging and Developed Market Contexts: Resource-Based and Organizational Learning Perspectives. Academy of Management Journal, v.43, p.449-467, 2000.

JARILLO, J. C. On strategic networks. Strategic Management Journal, vol. 9, n.1, p.3141, 1998.

KHANNA, T.; GULATI, R.; NOHRIA, N. The dynamics of learning alliances: Competition, cooperation, and relative scope. Strategic Management Journal, v.19, p.193-210, 1998.

REAd | Porto Alegre - Edição 78 - N² 2 - maio/agosto 2014 - p. 305-340 
Leander Luiz Klein \& Breno Augusto Diniz Pereira

KEIL, T. Strategic Alliances - A Review of the State of the Art. Helsinki University of Technology, Institute of Strategy and International Business. Working Paper Series, 2000.

KLEIN, L. L. ; PEREIRA, B. A. D. . Por que as empresas saem de redes? Contribuições para formação, gestão e fortalecimento de redes interorganizacionais. In: EnANPAD-2012 - Rio de Janeiro, Anais.. Rio de Janeiro, 2012.

KLINE, R. B. Principles and practices of structural equation modeling. New York: Guilford, 1998.

KOGUT, B. Joint-Ventures: Theoretical and Empirical Perspectives. Strategic Management Journal, v.9, n.4, p.312-332, 1988.

KOZA, M. P.; LEWIN, A. Y. Managing partnerships and strategic alliances: Raising the odds of success. European Management Journal, v.18, p.146 -151, 2000.

LARSON, R., BENGTSSON, L.; HENRIKSSON, K.; SPARKS, J. The Interorganizational Learning Dilema: Collective Knowledge Development in Stratégics Alliances. Organizations Science, (Special Issue). v.9, n.3, p.285-305, 1998.

LAWRENCE, T. B.; WICKINS, D.; PHILLIPS, N. Managing legitimacy in ecotourism. Tourism Management, v.18, n.5, p.307-316, 1997.

LIMA, P. E. S. Redes Interorganizacionais: uma análise das razões de saída das empresas associadas. 2007. 105 f. Dissertação (Mestrado em Administração) - Universidade Federal de Santa Maria, Santa Maria, 2007.

LIN, Z.J.; YANG, H.; ARYA; B. Alliance partners and firm performance: resource complementarity and status association. Strategic Management Journal, v.30, n.9, p.921-940, 2009.

LOURENZANI, A. E. B.; SILVA, A. L.; AZEVEDO, P. F. O Papel da Confiança na Construção de Ações Coletivas; Um estudo em Redes de suprimento de alimentos. In: ENANPAD, 30., 2006, Salvador. Anais... Salvador: ANPAD, 2006. 
Contribuições para a gestão de redes interorganizacionais: fatores determinantes para a saída de empresas parceiras

MOELLER, K. Partner selection, partner behavior, and business networkperformance: An empirical study on German business networks. Journal of Accounting \& Organizational Change, v. 6, n.1, p. $27-51,2010$.

MUTHUSAMY, S. K.; WHITE, M. Learning and knowledge transfer in strategic alliances: A social exchange view. Organization Studies, v.26, n.3, p.415-441, 2005.

OLSON, M. The Logic of the Collective Action: Public Goods and the Theory of Groups. President and Fellows of Harvard College. 1971. 185 p.

OLSON, M. A lógica da ação coletiva: os benefícios públicos e uma Teoria dos Grupos Sociais. São Paulo: EDUSP, 1999.

OSTROM, E. Governing the Commons: The Evolution of Institutions for Collective Action. Cambridge, UK: Cambridge University Press, 1990.

PARAST, M.M.; DIGMAN, L. A. Learning: the interface of quality management and strategic alliances. International Journal of Production Economics, v.114, n.2, p.820-829, 2008.

PARDINI, D. J.; SANTOS, R. V.; GONÇALVES, C. A. A dinâmica da aprendizagem intra e interorganizacional: perspectivas em estratégias cooperativas e competitivas utilizando as tipologias de exploration e exploitation. Revista Economia e Gestão, v.8, n.18, p.134-150, 2008.

PARK, S. H.; UNGSON, G. R. Interfirm Rivalry and Managerial Complexity: a conceptual framework of alliance failure. Organization Science, v. 12, n. 1, p. 37-53, 2001.

PARK, S. H.; CHEN, R.; GALLAGHER, S. Firm resources as moderators of the relationship between market growth and strategic alliances in semiconductor start-ups. Academy of Management Journal, v.45, p.527-545, 2002.

PEREIRA, B. A. D. Estruturação de Relacionamentos Horizontais em Rede. 2005. 219 f. Tese (Doutorado em Administração). Universidade Federal do Rio Grande do Sul, Porto Alegre, 2005. 
Leander Luiz Klein \& Breno Augusto Diniz Pereira

PEREIRA, B.A. D.; VENTURINI, J. C.; WEGNER, D.; BRAGA, A. L. Desistência da cooperação e encerramento de Redes Interorganizacionais: em que momento essas abordagens se encontram? RAI - Revista de Administração e Inovação, v.7, n.1, p. 62-83, 2010 .

PESÄMAA, O. Development of relationships in interorganizational networks: Studies in the tourism and construction industries. Unpublished Doctor's thesis, Luleå University of Technology, Strömsund, Sweden, 2007. Disponível: http://mpra.ub.unimuenchen.de/8478/1/MPRA_paper_8478.pdf >, Acessado em: 13/07/2011.

PFEFFER, J.; SALANCIK, G. The external control of organizations: a resource dependence perspective. New York: Harper \& Row, 1978.

PROVAN, K. G.; KENIS, P.; HUMAN, S. E. Legitimacy Building in Organizational Networks. p. 121-137. In L. BLOMGREN B.; O’LEARY, R. (eds.) Big Ideas in Collaborative Public Management. Armonk, NY: M.E. Sharpe. 2008.

SADOWSKI, B.; DUYSTERS, G. Strategic technology alliance termination: An empirical investigation. Journal of Engineering and Technology Management, v.25, p.305 - 320, 2008.

SAMPIERI, R. H.; COLLADO, C. F.; LUCIO, P. B. Metodologia de pesquisa. São Paulo: McGrall-hill Interamericana do Brasil Ltda, 2006.

SHENG-YUE, H.; XU, R. Analyses of strategic alliance failure: a dynamic model. In: International Conference on Management Science and Engineering - ISTP, 2005, Harbin Institute of Technology, Russia, 2005.

SOMFLETH, N. Stronger together: Small and medium sized tour operators in a horizontal network. 2011, ..f Master thesis, Suécia, University of Lund, Campus Helsingborg, 2011.

THEURL, T. From corporate to cooperative governance. In: THEURL, T. Economics of interfirm networks. Tübingen: Mohr Siebeck, 2005. Cap.3, p.149-192.

TIWANA, A. Do bridging ties complement strong ties? An empirical examination of alliance ambidexterity. Strategic Management Journal, v.29, p. 251-278, 2008. 
Contribuições para a gestão de redes interorganizacionais: fatores determinantes para a saída de empresas parceiras

TOIGO, T.; ALBA, G. R. Programa Redes de Cooperação do estado do Rio Grande do Sul: Perfil das Redes de Empresas acompanhadas pela Universidade de Caxias do Sul. XIII Semead - Seminários em Administração. Anais... São Paulo, Edusp, 2010.

TSANG, E. W. K. Acquiring knowledge by foreign partners from international joint ventures in a transition economy: Learning-by-doing and learning myopia. Strategic Management Journal, v.23, p.835-854, 2002.

TRIANDIS, H. C. Individualism and Collectivism. Boulder, CO: Westview, 1995.

UZZI, B. The sources and consequences of embeddedness for the economic Performance of Organizations: The Network Effect. American Sociological Review, vol. 61, p. 674-698, 1996.

VAN SLYKE, D. M. Agents or Stewards: Using Theory to Understand the Government Nonprofit Social Service Contracting Relationship. Journal of Public Administration Research and Theory, v.17, n.2, p.157-187, 2007.

VERSCHOORE, J. R.; BALESTRIN, A. Fatores Relevantes para o Estabelecimento de Redes de Cooperação entre Empresas do Rio Grande do Sul. Revista de Administração Contemporânea (RAC), v. 12, n. 4, p. 1043-1069, Out./Dez, 2008.

WEGNER, D.; PADULA, A. D. Governance and Management of Horizontal Business Networks: An Analysis of Retail Networks in Germany. International Journal of Business and Management, v. 5, n. 12, p. 74-88, 2010.

WEGNER, D.; ZEN, A. C.; ANDINO, B. F. A. O Último que Sair Apaga as Luzes: Motivos para a desistência da cooperação interorganizacional e o encerramento de redes de empresas. In: XI SEMEAD - Seminário de Administração, 2008, São Paulo, Anais..São Paulo, 2008 .

WESTERLUND, M.; RAJALA, R. Learning and innovation in inter-organizational network collaboration. Journal of Business \& Industrial Marketing, v.25, n.6, p.435-442, 2010.

WILLIANSON, O. E. The Economic Institutions of Capitalism. New York: Free Press, 1985.

ZAND, D. E.. Trust and Managerial Problem Solving. Administrative Science Quarterly, v. 17, p. 229-239, 1972.

REAd | Porto Alegre - Edição 78 - N² 2 - maio/agosto 2014 - p. 305-340 